\title{
SPubsaúde
}

\section{0 enfermeiro e o paciente}

\author{
The nurse and the patient
}

Luciana Figueiredo Santos"

\begin{abstract}
Curso de Enfermagem, Universidade Anhembi Morumbi, São Paulo, São Paulo, Brasil. *Autor para correspondência. Email: luciana.lfi@gmail.com
\end{abstract}

\section{Ponto de vista}

Através dos tempos, o papel da enfermeira foi mudado, porque o próprio paciente passou a ter uma interpretação mais completa do problema da saúde.

Antigamente, a enfermeira servia unicamente para mitigar o sofrimento humano e o acompanhamento que ela fazia era muito limitado, já que s programas de saúde não ofereciam um campo para desenvolvimento dos objetivos da profissão.

Atualmente as coisas mudaram: a função da enfermeira é mais ampla porque, além de promover acompanhamento do tratamento instituído pelo médico ela também promove a melhora da saúde do paciente através do ensino e dos conselhos.

Também o apoio e a reabilitação que a profissão da enfermagem oferece atualmente levam cada vez mais a solidificar sua posição no mecanismo de saúde da pessoa. A enfermeira geralmente é a primeira pessoa que aparece no atendimento do paciente que entra no sistema de saúde.

$O$ atendimento inicial, e também a orientação preventiva da enfermeira, atuam em forma interdependente com outros profissionais de saúde.

Mas pelo fato de que a enfermeira pode atuar em muitas frentes, dentro e fora dos hospitais, nas escolas, nas fábricas, na comunidade, sua prática se torna um vasto campo de expansão permanente.

Por estas razões, a enfermeira deve demonstrar habilidade e perícia na sua profissão. Deve estar atualizada nas novas técnicas, e ser muito competente na coleta de dados do paciente, da família dele, e também dos problemas da comunidade e dos grupos onde o paciente desenvolve suas atividades.

A enfermeira deverá adquirir esta experiência na sua continua educação durante a vida profissional.

Em relação ao paciente, ele é a figura central. Quando recorre a um serviço de assistência vem como indivíduo, como membro de uma família e como integrante de um grupo comunitário.

Ele chega sobrecarregado de preocupações pessoais e familiares, que estão misturadas com a enfermidade. Considera que seus problemas são intransponíveis, que devem ser solucionados, embora, a seus ver, eles não tenham solução possível. Pode misturar os problemas reais com problemas de menor importância.

A principal função da enfermeira é ajustar este paciente a classificar seus problemas, reduzi-los as proporções reais, e assim, pode enfrenta-los devidamente.

A primeira coisa que o paciente enfrenta como problema é o sintoma.

Se está com dificuldade para respirar, se a dispinéia é o elemento mais visível inicialmente, a enfermeira deverá entender este aspecto, e para aliviar a situação deverá estar ciente de todo o componente fisiopatológico que a dispinéia apresenta.

Além do sintoma-doença, existe o elemento segurança. O paciente pode se sentir inseguro, considerar sua doença como uma ameaça. Aqui a enfermeira, conhecendo a natureza da enfermidade, as possíveis complicações, poderá acompanhar o paciente neste período difícil da vida ajudando-o a superar o problema.

É papel da enfermeira profissional reconhecer a individualidade e personalidade do paciente.

\section{A equipe de enfermagem}

O pessoal que rodeia o paciente e sua família está integrado por diferentes partes de um grupo destinado a seu atendimento. 
Entre eles está a enfermeira, profissional que geralmente não está isolada. Sua equipe está integrada por uma enfermeira chefe que é altamente qualificada e deverá coordenar os planos de assistência.

$\mathrm{Na}$ equipe existem outras enfermeiras profissionais, estudantes de enfermagem e assistentes de enfermagem.

\section{A enfermeira chefe}

Deve planear e avaliar o cuidado de cada paciente. Orienta e apoia as atividades do grupo que chefia. Ela deverá tomar decisões judiciosas, e conhecerá amplamente os temas de educação sanitária e estará atualizada nas novas técnicas de enfermagem.

Pode também colaborar com o resto da equipe, no atendimento dos pacientes.

\section{A estudante de enfermagem}

Pode colaborar de acordo com o grau de instrução que possui no momento. Está situação é ambivalente, porque determina benefício para os pacientes de que ela pode cuidar e também para si mesma, porque ajuda na sua aprendizagem.

\section{A enfermeira prática e a assistente de enfermagem}

Desenvolve suas atividades de acordo com sua informação profissional, sua experiência clínica e sua competência pessoal.

O pessoal da enfermagem deve sempre efetuar uma reunião de equipe para trocar informações sobre cada paciente.

Essa reunião deve ser diária, realizada num período posterior ao atendimento principal dos pacientes. O chefe de equipe fará as anotações, aceitando as sugestões dos participantes da reunião.

$\mathrm{O}$ paciente pode se beneficiar desta troca de informações, do conhecimento acumulado do pessoal da equipe, porque - em conjunto - o trabalho de enfermagem será realizado da melhor forma possível.

O planejamento do atendimento do paciente

Quando o paciente chega ao hospital com um problema, o primeiro passo a dar é procurar saber se se trata de um caso simples ou complexo.

O médico avalia o paciente, conduz o exame, pede os dados de laboratório e os demais e prescreve o regime terapêutico a desenvolver.

Este planejamento deverá ser realizado pela enfermeira que terá a responsabilidade do cumprimento de todos os pontos determinados pelo médico.

A vantagem da enfermeira é que ela ficará muito perto do paciente começando pela coleta de dados com respeito a doença.

Aqui entra a parte mais importante para a enfermeira: a avaliação de enfermagem, que sintetiza o planejamento dos cuidados do paciente começando pela coleta de dados com respeito a doença.

\section{Coleta de dados}

É o primeiro passo para sintetizar o quadro clínico.

Começa pela história do paciente, obtida a partir de uma entrevista e que a enfermeira submete o paciente.

Quando está bem desenvolvida, a história apresenta a versão do paciente sobre:

Seus problemas de saúde.

História de alguma patologia anterior.

Um perfil da vida do paciente e da família.

Também algo muito importante é saber o que o paciente espera dos cuidados médicos que está procurando.

Esta história é subjetiva, porque determina só o ponto de vista do paciente e não os achados do entrevistador.

\section{Exame físico}

Este sim, é um aspecto objetivo desenvolvido pelo entrevistador para:

Comparar a história do paciente

Encontrar outros dados não relatados pelo paciente. 
E, fundamentalmente, obter elementos concretos para montar o quadro clínico da doença percebido pelo entrevistador.

\section{Dados laboratoriais}

Estes testes também fazem parte do conglomerado objetivo.

A coleta de dados obedece a certos princípios:

Deve ser bem organizada.

Deve ter uma ordem para se poder dizer que é completa.

Não pode haver preconceitos, porque poderiam passar desapercebidos muitos dados de importância.

A técnica deverá ficar registrada, de modo que todos os membros da equipe tenham acesso aos mesmos dados e possam orientar em conjunto o tratamento do paciente.

O registro dos dados reunidos é um documento legal. Deve ser conciso, complexo e claro. Deve evitar redundâncias e repetições.

\section{Princípios de elaboração do registro}

O registro se elabora logo que a informação for colhida.

O primeiro que se registrará é a informação subjetiva do paciente.

Depois se registra o exame físico. Os dados registrados devem ser descritos com terminologia apropriada e compreensível para qualquer leitor.

Não usar abreviaturas.

O juízo que se possa emitir será feito unicamente após os dados estarem reunidos e avaliados com muito cuidado. O documento deverá estar assinado e datado.

A história clinica deve ser registrada da mesma maneira. Deverá existir uma cronologia da doença de modo que o pessoal que trata do paciente saiba realmente como e quando começou a mesma.

É muito importante, quantificar os sintomas - "Vomitou três vezes" etc.

No exame físico serão observadas todas as anormalidades presentes e devidamente registradas. Não deverão ser descritos os achados normais.

Unicamente devem ficar registradas condições que, estando normais, deveriam estar anormais no quadro clínico. Ex: "num caso de hipertensão, descreve-se a não existência de exsudatos no exame de fundo do olho, por exemplo.

Os resultados de laboratório se seguem ao exame físico e antecedem a avaliação final.

\section{A evolução do paciente}

O Paciente que ficou enquadrado dentro da avaliação pela enfermeira com a correspondente documentação registrada (coleta de dados, testes laboratoriais, etc.) deverá continuar dentro do registro sendo seguida a evolução da sua doença de forma metódica e precisa.

Cada consulta médica, cada turno de enfermagem, deverá registrar sua observação e impressão profissional do caso. Para tanto, existe atualmente um critério definido onde se considera necessário registrar numa papeleta médica os problemas específicos que são catalogados e até numerados durante a evolução do caso.

Este registro orientado para o problema, elaborado nos E.U.A. pelo Dr Lawrence Weed, pode variar em determinadas condições particulares, mas em geral, se forma a partir de dados básicos iniciais.

Eles consistem de: - primeiramente, a história clínica do paciente.

Exame físico completo

Dados laboratoriais.

\section{Os problemas}

Deve-se formar uma lista numerada de todos os problemas médicos, psicológicos e sociais que possam aparecer através dos elementos básicos iniciais. Deverão ser acompanhados da data de aparição deles e se foram resolvidos ou não. Na prática, esta lista deve ser considerada como um índice. Evitar repetir os números, aparecendo novos problemas, eles terão numeração sequencial. 
Na evolução, efetuam-se anotações que podem ficar sintetizadas:

S - Dados subjetivos dentro da evolução.

O - Dados objetivos que abrangem o mesmo período.

A - Avaliação - inclui as conclusões (etiologia, resposta do paciente ao tratamento e também seu comportamento com relação ao plano).

Deve incluir uma conclusão sobre a reação ao plano de tratamento, por parte do paciente

P- Plano: costa de três aspectos:

Diagnostico - o que deve ser feito.

Terapêutico - serve para projetar os métodos paliativos ou curativos.

De educação médica - permite obter conclusões para melhorar os conhecimentos e o médico.

\section{Implementação do tratamento}

É a execução do mesmo, incluem-se todas as atividades de enfermagem que possam ajudar a melhorar a doença e ao mesmo tempo atendem as necessidades e problemas do paciente.

Entre todas as atividades - incluindo o conforto do paciente, sua higiene diária, melhora de suas funções respiratórias, a boa eliminação urinária e intestinal - a enfermeira deverá observar para que exista normalidade do meio ambiente, inclusive, se estão sendo cumpridas as normas básicas de educação sanitária etc.

O médico prescreve os medicamentos, porém a enfermeira deve aplicar seus conhecimentos de fisiologia para enfrentar determinadas circunstâncias, quando então unicamente as medidas que ela possa adotar poderão melhorar a situação do paciente.

É o caso do hipertenso, que está recebendo prescrição adequada e que bruscamente começa com forte cefaleia. A enfermeira então mede a pressão e observa algumas alterações por elevação da mínima ou pressão diastólica. Ela, ao considerar que o fator de depleção urinária melhora rapidamente o quadro, poderá instituir uma medicação adequada e comunicar o fato ao médico.

As notas de progresso do paciente deverão ser escritas num formulário especial, que será levado sem erros e com relação clara de todos os achados por parte da enfermeira, e onde também se deverão registrar os passos que foram tomados para solucionar os diversos problemas.

Estas notas, escritas como se fosse uma narrativa, respeitam aquela sequência: dados subjetivos, objetivos, avaliação, plano, intervenção por parte da enfermeira e a apreciação final sobre os resultados. Eles são da máxima importância porque promovem de minuto a minuto uma avaliação de todo o processo de atendimento ao paciente.

Qualquer observador poderá encontrar nelas os erros ou as decisões insuficientes no atendimento ao paciente, para poder efetuar a correspondente correção do tratamento.

Estas folhas não melhoram o tratamento, mas podem resolver em instantes onde está o ponto de atrito com relação a evolução do quadro clínico. Daí sua importância essencial.

Assim, como conclusão, quando o paciente tem alta, ou é transferido, é fundamental que estas notas sejam complementadas por um resumo total do problema, incluindo a etiologia, a evolução, os planos futuros que o paciente poderá aplicar em casa ou que serão aplicados noutro hospital.

Este resumo é feito pelo médico responsável, e abrange a contribuição dos demais profissionais, que contribuíram para resolve os problemas do paciente.

A enfermeira está autorizada a registar sua contribuição no resumo, quando o médico não estiver em condições de fazê-lo, em nome do resto da equipe.

Palavras-chave: enfermagem, paciente, problemas, evolução do paciente.

Keywords: nursing, patient, problems, evolution of the patient.

\section{Referências}




\section{Minicurrículo}

Luciana Figueiredo Santos. Engenheira em Telecomunicações a 21 anos, área de atuação Telefônica Móvel Celular, Operações Móveis, cursando o terceiro ano Bacharel de Enfermagem na Universidade Anhembi Morumbi. Atualmente se dedica a área de enfermagem nos estudos de conceitos, normas, processos, práticas de enfermagem e protocolos de saúde, junto ao COFEN e demais instituições da área.

Como citar: Santos, L.F. 2020. O enfermeiro e o paciente. Pubsaúde, 3, a029. DOI: https:// dx.doi.org/10.31533/pubsaude3.a029

Recebido: 15 abr. 2020.

Revisado e aceito: 16 abr. 2020.

Conflito de interesse: os autores declaram, em relação aos produtos e companhias descritos nesse artigo, não ter interesses associativos, comerciais, de propriedade ou financeiros que representem conflito de interesse.

Licenciamento: Este artigo é publicado na modalidade Acesso Aberto sob a licença Creative Commons Atribuição 4.0 (CC-BY 4.0). 